\title{
SECOND-ORDER P- $\Delta-\delta$ ANALYSIS AND DESIGN OF ANGLE TRUSSES ALLOWING FOR IMPERFECTIONS AND SEMI-RIGID CONNECTIONS
}

\author{
S.L. Chan* and S.H. Cho \\ *Department of Civil and Structural Engineering, \\ The Hong Kong Polytechnic University, Hong Kong \\ Email: ceslchan@polyu.edu.hk Fax: (852) 23346389
}

\begin{abstract}
Single angle members have a broad range of applications, such as web members in roof trusses and bracing members in latticed towers. The structural behaviour of a single angle compression member in a truss is complicated. It is not uncommon to connect one angle member to another through their legs. Therefore, in practice, the member is under an eccentric force which introduces a pair of end moments. However, in most design codes such as BS5950 (2000) and Eurocode 3 (2003), these end moments are often ignored. To compensate for this load eccentricity, the Robertson constant in the Perry-Robertson formula is amplified so that the compressive strength is reduced for the negligence of end eccentricities. In this method of analysis, all connections are assumed to be pin-jointed; while in the design, the effective length is assumed on the basis of connection types (e.g. single-bolted, double-bolted or welding) which violates the assumption in the analysis. This paper proposes a design method for angle trusses using nonlinear analysis which eliminates the inconsistency between the analysis and the design. Laboratory tests of angles as web members of a truss were carried out. The test results are compared with the proposed theoretical and code design loads. In the proposed design method, there is no need to consider any effective length. The second-order P- $\Delta$ and P- $\delta$ effects are considered automatically by geometry update. The proposed method is readily applicable to design of practical steel trusses made of angle sections.
\end{abstract}

Keywords: Eccentricity, effective length, initial curvature, nonlinear analysis, second-order effects

\section{INTRODUCTION}

Second-order and advanced analysis of steel buildings has been extensive with its concept is well established (Chen and Lui [1]), but this type of analysis for angle trusses is limited. Single angle members in compression have a broad range of applications, such as web members in roof trusses, members in latticed towers and bracing members, etc. Single angles are widely used because of their ease of fabrication, erection and transportation. It is not uncommon to connect one angle member to a gusset or another member through one leg. Therefore, in practice, the member is under an eccentric force which introduces a pair of end moments reducing the load capacity of the angle member. However, the connection at ends normally provides restraining moments which are beneficial to the compressive resistance of the angle. The above-mentioned features are unique to angle sections making the analysis of angle members complicated. Moreover, the sections are either mono-symmetric for equal-leg angles or asymmetric for unequal-leg angles, the principal planes are almost always inclined to the loading planes. They may fail in a complex mode involving bending about both principal axes with simultaneous twisting about the shear centre. To achieve the exact elastic solution of an angle with end restraints and eccentric compressive load, a close-form solution is hardly possible and numerical methods must be adopted. Trahair [2] carried out a theoretical investigation on elastic biaxial bending and torsion of beam-columns with symmetric end loading and restraints. These end conditions are close to the ones in practical structures. The differential equilibrium equations for principal major axis bending, principal minor axis bending and torsion have been given by Goodier [3,4], and the problem was solved by using the finite integral method 
(Trahair, [2]). The structural behaviour of eccentrically loaded end restrained single angle struts was studied and compared with experimental data reported by Foehl [5]. It was shown that the first yield loads are quite close to the failure load and may be used as conservative estimates of the ultimate strengths of the single angle struts. It should be noted that when using the interactive formula for axial force and moment in conjunction with the use of elastic modulus, the checking becomes the first-yield load check. When the plastic modulus is used, the checking then becomes section capacity check.

Kitipornchai and Chan [6] employed an alternative approach based on the finite element method to solve the problem of elastic analysis of restrained beam-columns. The total potential energy for thin-walled beam-column was formulated, incorporating member geometrical nonlinearity. The element geometric stiffness matrix for angles was derived. The equilibrium paths were then determined from the incremental and the total force-deformation equilibrium equations. The influence of the pre-buckling deformations was incorporated in the analysis by modifying the structural tangent stiffness continuously through geometry updates. The results were compared with those reported by Trahair [2]. It was found that when the geometry was not updated, the results were found to agree well with the finite integral solutions by Trahair [2]. However, when the geometry was updated, the influence of the pre-buckling deformations was apparent in some orientation of the restraint plane indicating that the conventional numerical procedure may grossly overestimate the actual member capacity. This indicates the importance considering the finite deflection effect. However, these two approaches were seldom used in practice as they were time consuming and thus unsuitable for designing large scale trusses. Instead, the linear analysis in annotation with the effective length method was adopted conventionally.

On top of theoretical studies, a great deal of research has been conducted on testing of angle members in compression and the results were compared with some of the American design codes. Trahair et al. [7] carried out theoretical and experimental studies on the design of eccentrically loaded single-angle steel columns. The tests were performed on equal and unequal angles under various end restraint conditions. The theoretical solutions of elastic analysis were found to agree well with the test results and can be used as a lower bound estimate of the actual failure loads. Adluri and Madugula [8] compared experimental results on eccentrically loaded single angle members free to rotate in any directions at ends with the available literature with AISC LRFD [9] and AISC ASD [10] specifications. The experimental investigations, which cover a wide spectrum of single angle struts, were carried out by Wakabayashi and Nonaka [11], Mueller and Erzurumlu [12], and Ishida [13]. It was concluded that the interaction formulas given in AISC LRFD [9] and AISC ASD [10] are highly conservative when applied to eccentrically loaded single angle members. Bathon et al. [14] carried out 75 full-scale tests which cover a slenderness ratio ranging from 60 to 210. The test specimens were unrestrained against rotation and twist at the end supports. It was noted that the ASCE Manual 52 [15] under-predicts the capacities of single angle struts. The conservatism of the interaction formulas are due to the fact that these formulas were derived primarily for doubly symmetric sections and the moment ratios in these formulas are evaluated for the case of maximum stresses about each principal axis. This practice does not pose a problem on doubly symmetric sections such as I sections because the four corners are critical for moments about both principal axes simultaneously. However, for angle sections, as they are mono-symmetric or asymmetric, the points of maximum bending stress about both principal axes usually do not coincide. As a consequence, the load capacities of the sections calculated from these interaction formulas are underestimated (Adluri and Madugula [8]). 
The above-mentioned research work focuses only on isolated members with ideal end conditions. Although different end conditions were considered (e.g. pinned or fixed-end), the actual end conditions may not be truly reflected. To model accurately the actual end conditions, Elgaaly et al. [16] conducted an experimental program to investigate the structural behaviour of non-slender single angle struts as part of three-dimensional trusses. The specimens cover a range of slenderness ratio from 60 to 120. Results also show that both the ASCE Manual 52 [15] and AISC LRFD [9] are over-conservative for single angle members with low slenderness ratio.

In this paper, a new design method for angle trusses is derived and incorporated into a nonlinear analysis computer program (NIDA [17]), which allows for the practical nature of external forces and structures such as load eccentricity and initial imperfections. Because of the availability of low-cost personal computers, this computer method can be applied to design of a wide range of angle trusses to-date. The validity and the accuracy of the proposed method are demonstrated through two laboratory tests of trusses with single angles as web members. The test results are compared with the theoretical solutions and with the current design method to BS5950 [18]. The advantage of the proposed method lies on its accurate computation of moment and axial force on a section due to eccentric moments about the two principal axes and its flexibility of modelling the equivalent initial imperfection in substitution for the combined effect of geometrical imperfection and residual stresses. The results reported in this paper may provide reference to member imperfection for this type of asymmetric sections recommended in steel design codes with advanced topics, which include the latest Euro-code 3 [19] and the Hong Kong Steel Code [20], on second-order and advanced analysis.

\section{CONVENTIONAL DESIGN METHOD - BS5950 (2000)}

When angles are used as web members of trusses, the members are usually attached to gusset plates or to the chord members through one leg. In addition, the principal axes are often inclined to the loading axes. Therefore, the load acting to the angle is always away from the centroid of the section such that these members are subject to end eccentricities about two principal axes in practice. As a result, theses angles may fail in a complex mode involving axial shortening, biaxial bending and twisting. Despite the wide-spread use of single angles as compression members, the design procedures in many national design codes such as BS5950 [18] and Euro-code 3 [19] are often over-simplified. To simplify the design procedure, in BS5950 [18], Clause 4.7.10 allows the engineers to design these members as simple compression members without end eccentricity. Instead, the end eccentricity is represented qualitatively by amplifying the Robertson constant in the Perry-Robertson formula so that the compressive strength is reduced in order to compensate the effect due to end eccentricity. There are basically two stages in the design procedure. In the analysis stage, a linear analysis is performed and deformation is assumed small so that the load-deformation relationship can be neglected and the connections are pin-jointed. With the output of member forces, the "effective length" of individual member is assumed in the second design stage in accordance with the connection type. Summarizing the consideration of effective length recommended in BS5950 [18], the "effective length" factor is 1.0 for single-bolted end connection and 0.85 for end connection with two or more bolts. The compressive resistance of the member is calculated from this assumed "effective length". The structure is deemed to be adequately safe if the compressive resistance is larger than the applied force. However, the "effective length" assumption in the design stage contradicts with the pin-jointed connection assumption in the analysis stage. It is realized that 
any gross under-estimation of effective length may lead to a catastrophic collapse. On the other hand, material will be wasted if the compressive strength is under-estimated.

\section{SECOND-ORDER P- $\Delta-\delta$ DESIGN METHOD}

In the proposed design method, the nonlinear analysis software NIDA [17] is modified. As indicated in its user manual [17]. A few assumptions have been made for the computer analysis as follows.

(1) The assumed failure mode is flexural buckling about the principal minor axis. Therefore the initial imperfection is imposed about the principal minor axis so that bending about the principal minor axis is initiated. The other failure mode like the flexural-torsional buckling is not directly considered in the investigation but they may be included by separated member check since their behaviour has little interaction with other members in the frame.

(2) The effect of local buckling is ignored. Only Class 3 semi-compact or above angle sections are considered with only the extreme fibre in compression can be loaded to the design strength. However, if slender sections are used, it is suggested the equivalent sectional properties accounting for local plate buckling can be used and the remaining procedure can be followed.

One of the important features of software NIDA [17] is the initial curvature can be incorporated into the element. To the authors' knowledge, this inclusion of member imperfections is suggested explicitly in only two currently available design codes, the Euro-code 3 [19] and the Hong Kong Steel Code [20]. In this model, when the element is under pure axial load, both the axial shortening and bending due to member imperfection and curvature due to load will occur. In contrast, if a linear analysis is performed, only axial shortening can be modeled. During the nonlinear analysis, the $\mathrm{P}-\delta$ effect is taken into account by the imposition of the load-induced curvature to initial curvature throughout the analysis. Further, the P- $\Delta$ effect depending on nodal movement is considered by continuous modification of the structural geometry. The advantages of using the $\mathrm{P}-\Delta-\delta$ method include the followings.

(1) Effective length is not required to be guessed for computation of compressive strength of members of which a reliable "guess" for some buckling modes like snap-through buckling is not possible;

(2) The effective length approach of accounting for P- $\delta$ moment can only deal with the effect arisen from initial imperfection and the $\mathrm{P}-\delta$ moment induced by external load on member curvature cannot be allowed for by the effective length method. Additional reduction such as $\mathrm{B}_{1}$ factor in LRFD [9] is required and the design becomes tedious;

(3) Only one element per member is required for modeling since the element possesses curvature to mode $\mathrm{P}-\delta$ effect, leading to much convenience in model construction and in modeling of imperfect member required by the Euro-code 3 [19] and the Hong Kong Steel Code [20]; and

(4) The design is completed simultaneously with the analysis, thus time and effort spent by the design engineer can be greatly reduced. 


\section{MEMBER IMPERFECTIONS}

In BS5950 [18], the end eccentricity is replaced by an equivalent value of the Robertson constant. Similarly, in NIDA (2002), the end eccentricity is simulated by an equivalent value of initial curvature of the element. The value of initial curvature-to-length ratio $\left(\delta_{0} / \mathrm{L}\right)$ is controversial but generally in the same order across different codes. In this paper, the following formula derived basically from the Perry-Robertson formula is used (Chan and Cho, [21]).

$$
\frac{\delta_{0}}{L}=0.001 \times \frac{5.5}{y / r}
$$

in which $\quad \delta_{0}$ is the initial imperfection of the element

$\mathrm{L}$ is the element length

$\mathrm{y}$ is the distance from the centroid to the extreme fibre of the section

$r$ is the radius of gyration of the section

According to Eq. (1), depending on the sizes and leg ratios of angles, there are different values of $\delta_{0} / \mathrm{L}$ to account for the P- $\delta$ effect. However, for similar geometrical cross-sections, the values of $y / r$ are roughly constant. Therefore, for practical design purpose, only one single value of $\delta_{0} / \mathrm{L}$ is adopted for each section type (equal angle and unequal angle) for convenience which is obtained from the section having the smallest value of $\mathrm{y} / \mathrm{r}$ and thus the largest value of $\delta_{0} / \mathrm{L}$ so that the buckling strength calculated using this $\delta_{0} / \mathrm{L}$ value is slightly conservative to the actual buckling strength. Table 1 summarizes the design values of $\delta_{0} / \mathrm{L}$ for both equal and unequal angles.

Table 1. Recommended design values of initial imperfection about the minor axis

\begin{tabular}{c|c}
\hline Section Type & $\delta_{0} / L$ \\
\hline Equal Angle & $1 / 360$ \\
\hline Unequal Angle & $1 / 400$ \\
\hline
\end{tabular}

\section{CONNECTION SPRING ELEMENT}

In the convention design approach, the double-bolted connection of the compression angle is considered by assuming the "effective length" as 0.85 of the actual length of the member; while in the proposed approach, the double-bolted connection is modelled as a connection spring element shown in Figure 1 and inserted to the end of the angle member. Therefore, the rotational stiffness due to the double-bolted connection can be considered at the early stage of the analysis rather than at the design stage as in the linear analysis and effective length design method. Only the rotational deformation of the connection spring element is considered for design because the effects of the axial and shear forces in the connection deformations are small when compared with that of bending moments.

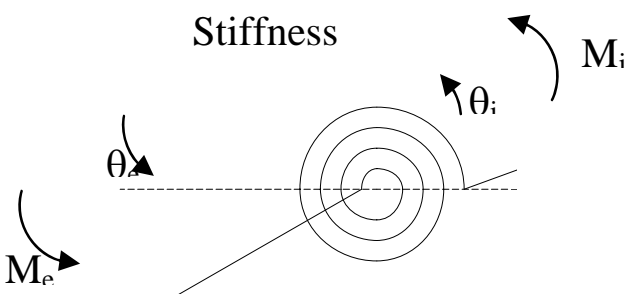

Figure 1. Connection spring element at one end of an element 
Referring to Figure 1 and considering equilibrium, the vector sum of moments on two ends of a connection spring element vanishes.

$$
M_{e}+M_{i}=0
$$

in which $M_{e}$ and $M_{i}$ are the external and internal moments at two ends of a connection. The external node refers to the one connected to the global node and the internal node is joined to the angle element. The stiffness of the connection, $S_{c}$, can be related to relative rotations at the two ends of the connection spring as

$$
S_{c}=\frac{M_{e}}{\theta_{e}-\theta_{i}}=\frac{M_{i}}{\theta_{i}-\theta_{e}}
$$

in which $\theta_{e}$ and $\theta_{i}$ are the conjugate rotations for the moments $M_{e}$ and $M_{i}$.

Eq. (3) can be re-written to an incremental tangent stiffness matrix form as

$$
\left[\begin{array}{l}
\Delta M_{e} \\
\Delta M_{i}
\end{array}\right]=\left[\begin{array}{rr}
S_{c} & -S_{c} \\
-S_{c} & S_{c}
\end{array}\right]\left[\begin{array}{l}
\Delta \theta_{e} \\
\Delta \theta_{i}
\end{array}\right]
$$

Eq. (4) will be superimposed to the element stiffness matrix so that the flexural rigidity of the connection can be accounted for during analysis.

\section{ANALYSIS PROCEDURE}

To determine the design and buckling load of a structure, approximately $1 \%$ to $10 \%$ of the predicted failure load is applied incrementally until the sectional capacity factor, $\varphi$, in Eq. (5) below is greater than 1 .

$$
\frac{P}{p_{y} A}+\frac{M_{y}+P\left(\Delta_{y}+\delta_{y}+\Delta_{0 y}+\delta_{0 y}\right)}{p_{y} Z_{y}}+\frac{M_{z}+P\left(\Delta_{z}+\delta_{z}\right)}{p_{y} Z_{z}}=\varphi
$$

in which $\quad p_{y}$ is the design strength normally taken as the yield stresses of the section,

$P$ is the external force in the section

$A$ is the cross-sectional area

$M_{y}$ and $M_{z}$ are the external moments about the y- and the z- axes

$M_{r y}$ and $M_{r z}$ are the moment resistance about the $\mathrm{y}$ - and the z- axes

$P\left(\Delta_{y}+\delta_{y}\right)$ and $P\left(\Delta_{z}+\delta_{z}\right)$ are the second-order $\mathrm{P}-\Delta-\delta$ moments about the $\mathrm{y}$ - and the $\mathrm{z}$ axes for large deflection effect and member bowing effect as well as their imperfections of which the consideration allows us to include automatically the effect of "effective length"

To be more accurate for economical design, Equation 5 should be applied to various points across the section using the corresponding moduli of those points considered with allowance for the sign of stress.

The Newton Raphson method combined with the minimum residual displacement iterative scheme (Chan, [22]) of solving the following set of nonlinear simultaneous equation as follows is utilized with the iterative scheme illustrated in Figure 2. 


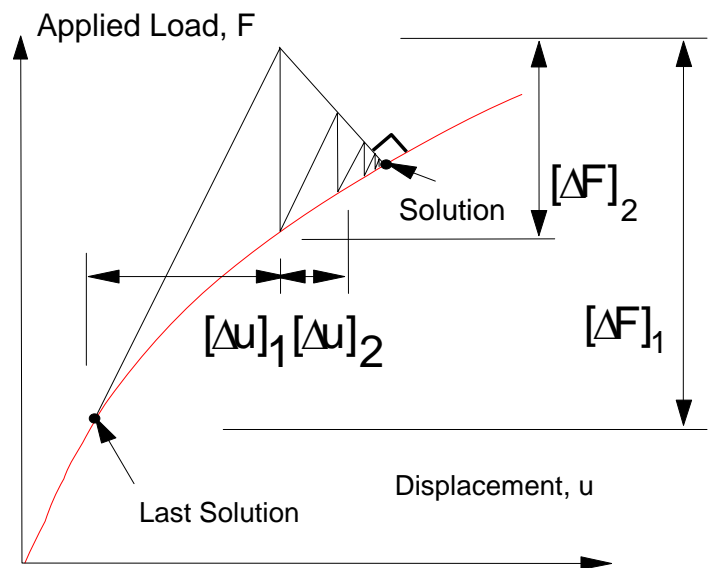

Figure 2. The Minimum Residual Displacement method

$$
\begin{aligned}
& {[\Delta \tilde{u}]=\left[K_{T}\left(u, \delta_{0}, F\right)\right]^{-1}[\Delta F]} \\
& {[\Delta \bar{u}]=\left[K_{T}\left(u, \delta_{0}, F\right)\right]^{-1}[\Delta \bar{F}]}
\end{aligned}
$$

The displacement incremental is determined as,

$$
[\Delta u]=[\Delta \tilde{u}]+\lambda[\Delta \bar{u}]
$$

in which $[\Delta \widetilde{u}],[\Delta \bar{u}]$ and $[\Delta u]$ are the displacement increments due to unbalanced force, applied load and summed displacement increment for calculation of unbalanced force. $\lambda$ is a parameter satisfying the minimum residual displacement condition (Chan [22]). Figure 3 shows the compressive strength curves of both equal and unequal angles of slenderness ratio ranging from 0 to 350 derived from NIDA [17] using the initial curvature values shown in Table 1, together with the BS5950 [18], compressive strength curve c (Table 24c) for comparison. It is found that, in lower slenderness range, the difference between the NIDA [17] curve and the BS5950 [18] curve is about 10\% but at the higher slenderness range two curves tend to be identical. It should be noted that practical angle struts usually belong to the intermediate to high slenderness range between 50 to 150 . This degree of accuracy is considered to be adequate for practical design.

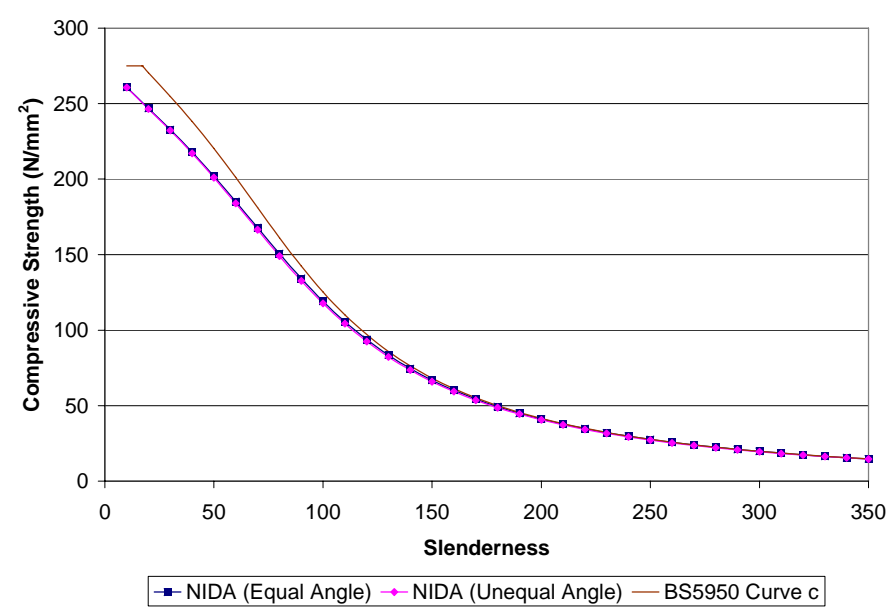

Figure 3. Compression strength curves 
To validate the accuracy of the method proposed in this paper and to study the structural behaviour of a slender angle web member of a truss, two $2000 \mathrm{~mm}$ long $65 \times 65$ x 6 single angle specimens of Grade S275 steel and slenderness ratio about 150 were tested as web members of a two dimensional simply supported truss shown in Figure 4. The leg length-to-thickness ratio meets the BS5950 [18] requirements so that local buckling can be ignored. Each end of the member is connected to a $240 \mathrm{x}$ $180 \times 8$ gusset plate. The two specimens were tested under single-bolted and double-bolted end conditions. The trusses were loaded in pair and sufficient lateral restraints were provided to ensure out-of-plane buckling at connecting nodes between chords and webs is fully avoided. Load was applied through a hydraulic jack. As shown in Figures 5 and 6, twelve strain gauges were mounted at the mid length of targeted member and the tested truss was so designed that the targeted member fails first. At the targeted member, two displacement transducers were placed in the in-plane and out-of-plane directions and transducers were also used to monitor the movements of the top and the bottom joints of the targeted member so that its movement relative to the truss can be measured. At the load where the target member buckled or failed, the deformations of the remaining parts of the truss were small and reversible. Thus, after the first test, the failed member was replaced by another new specimen so that the second test could be carried out under the almost the same conditions except with different bolting details at member ends.

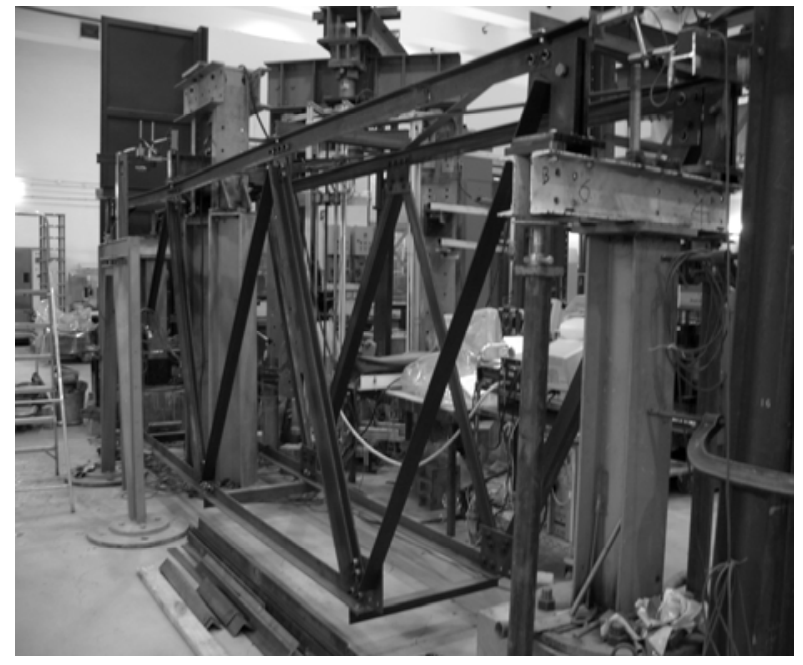

Figure 4. Truss before test

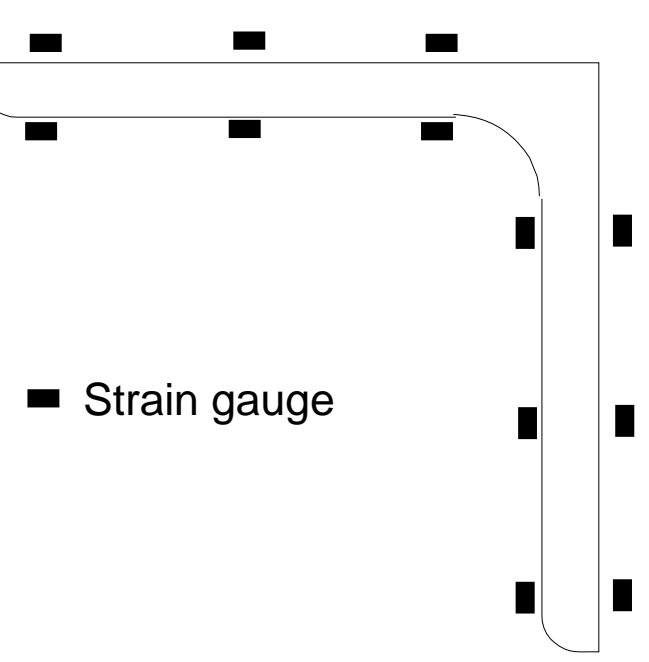

Figure 5. Locations of strain gauges

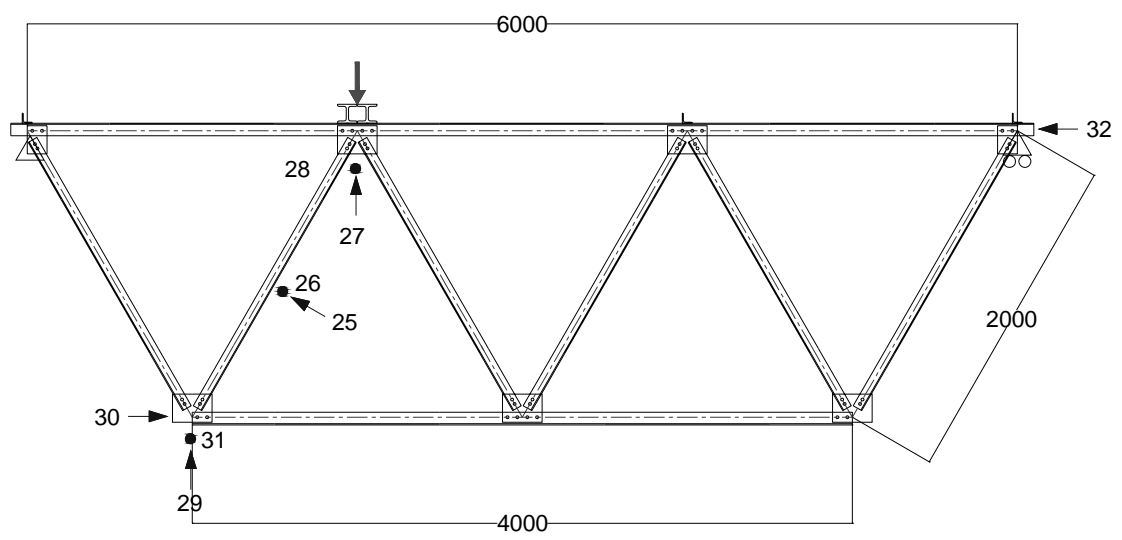

- Out-of-plane direction

$\rightarrow$ In-pane direction

Figure 6. Locations of the transducers 


\subsubsection{Material Properties}

Two coupon tests were performed to determine the material properties of the steel used in the test specimens following the procedure given in BS EN 10002-1 [23]. The tests gave consistent results which are summarized in Table 2.

Table 2. Coupon test results

\begin{tabular}{|c|c|c|}
\hline Coupon & $\begin{array}{c}\text { Young's modulus, E } \\
\left(\mathrm{kN} / \mathrm{mm}^{2}\right)\end{array}$ & Yield stress, $\sigma_{y}\left(\mathrm{~N} / \mathrm{mm}^{2}\right)$ \\
\hline 1 & 347.0 & 216.9 \\
\hline 2 & 347.6 & 211.8 \\
\hline Mean & 347.3 & 214.4 \\
\hline
\end{tabular}

\subsubsection{Test Results}

The observed failure modes are flexural buckling about the principal minor axis for both of the tests as shown in the photos (Figures 7 and 8). Figure 7 shows the failure mode of Specimen 1, of which each end is connected by one single bolt, making it to behave as if pin-ended. Figure 8 shows the failure mode of Specimen 2 of which each end is connected by two bolts. The gusset plate connected at each end provides some flexibility making it to behave as if partially restrained in the out-of-plane direction. Figure 9 shows the in-plane deformations while Figure 10 shows the out-of-plane deformations of the two specimens. Their response patterns are almost identical. As can be seen from the curves, the out-of-plane deformations are always more severe than the in-plane deformations. The member failure loads are calculated using numerical integration of the stress over the cross-sectional area and listed in Table 3. The failure load of the specimen with double-bolted end condition is approximately $12 \%$ higher than that with single-bolted end condition.

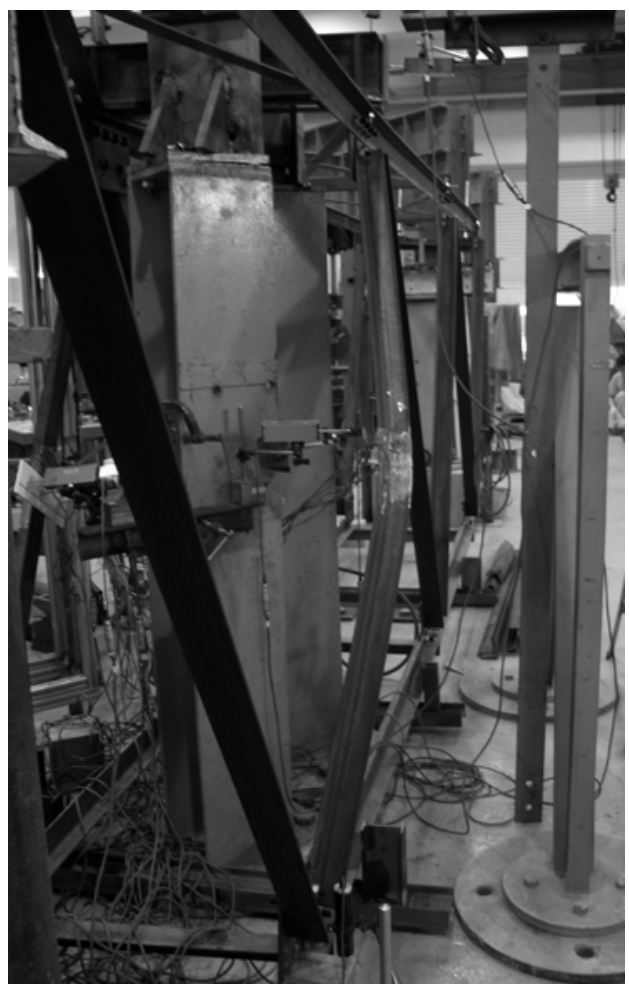

Figure 7. Flexural-buckling about the principal minor axis of Specimen 1

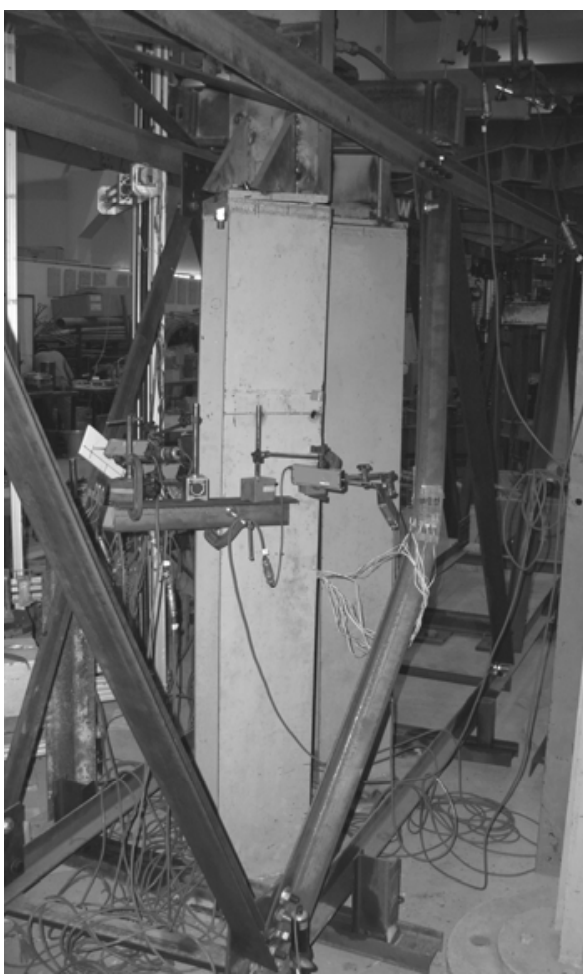

Figure 8. Flexural-buckling about the principal minor axis of Specimen 2 


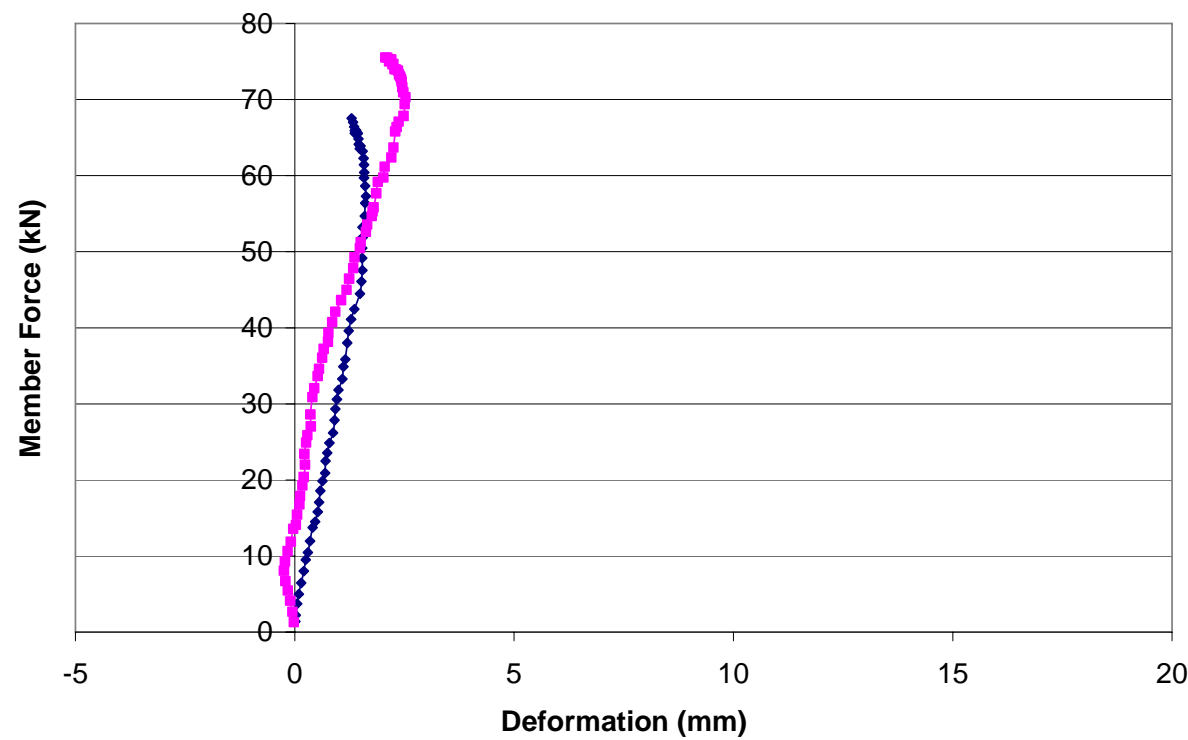

- Single-bolted Connection $-\backsim$ Double-bolted Connection

Figure 9. In-plane deflection of Specimens 1 and 2

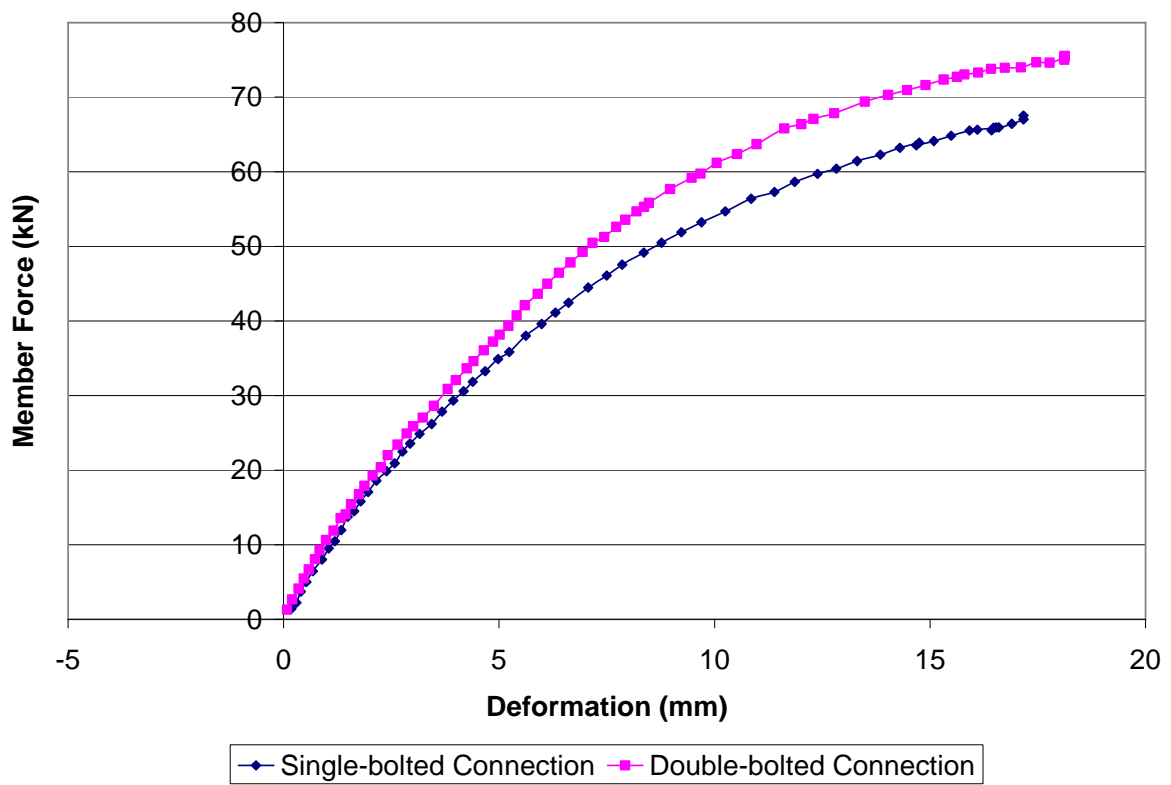

Figure 10. Out-of-plane deflections of Specimens 1 and 2

Table 3. Test failure loads of specimens 1 and 2

\begin{tabular}{c|c|c}
\hline Specimen & End Condition & Failure Load (kN) \\
\hline 1 & Single-Bolt & 67.5 \\
\hline 2 & Double-Bolt & 75.5 \\
\hline
\end{tabular}

The design loads from BS5950 [18] are compared with the experimental failure loads and the predicted failure loads by NIDA [17]. In predicting the failure load of the double-bolted specimen (Specimen 2) by NIDA [17], rotational springs of stiffness equal to the stiffness of the gusset plate are inserted to both ends of the element and the results are summarized in Table 4. It is found that the BS5950 [18] predicted failure loads are $40.6 \%$ and $11.8 \%$ lower than the tested failure load for 
single-bolted and double-bolted end conditions respectively. In other words, the BS5950 [18] provides a conservative but acceptable design loads for both cases.

Table 4. BS5950 [18] Failure Loads vs Experimental and NIDA [17] Failure Loads

\begin{tabular}{c|c|c|c|c|c|c}
\hline Specimen & $\begin{array}{c}\text { End } \\
\text { Condition }\end{array}$ & $\begin{array}{c}\text { BS5950 } \\
\text { Design } \\
\text { Load (kN) }\end{array}$ & $\begin{array}{c}\text { Experimental } \\
\text { Failure Load } \\
\mathbf{( k N )}\end{array}$ & $\begin{array}{c}\text { BS5950 \% } \\
\text { Difference } \\
\text { with Test }\end{array}$ & $\begin{array}{c}\text { NIDA } \\
\text { Failure } \\
\text { Load (kN) }\end{array}$ & $\begin{array}{c}\text { NIDA \% } \\
\text { Difference } \\
\text { with } \\
\text { BS5950 }\end{array}$ \\
\hline 1 & Single-Bolt & 40.1 & 67.5 & 40.6 & 39.3 & 2.0 \\
\hline 2 & Double- Bolt & 66.6 & 75.5 & 11.8 & 63.1 & 5.2 \\
\hline
\end{tabular}

The design load allowing for flexible end connection by NIDA [17] is $2 \%$ and $5 \%$ below the code results for single and double bolted conditions respectively.

In the current design method based on codes, isolated member behaviour and design are the normal focus. The analysis and design are carried out in two separated and independent stages. The calculation of the compressive strength of a single angle relies heavily on the assumption of the effective length factor $\left(\mathrm{L}_{\mathrm{e}} / \mathrm{L}\right)$ which is, however, limited to 1.0 and 0.85 respectively for single and double-bolted end conditions. In fact, if the two end nodes of the member move, the "effective length" factor is always larger than 1.0 and thus the conventional linear analysis method becomes unsafe.

\subsection{Example 2: Second-order analysis in a portal - an illustrative example for advantages}

The accuracy of the proposed approach using imperfect element has been demonstrated and the advantage of the present method over the conventional effective length method is illustrated in the example here. To allow clarity in this demonstration, a very simple portal braced by a pair of angle members is studied by the two approaches, the code method based on a linear analysis and the second-order $\mathrm{P}-\Delta-\delta$ analysis. As shown in Figure 11, the portal is 2 $\mathrm{m}$ high by $3 \mathrm{~m}$ wide with beams and columns of the same section of $305 \times 305 \times 240$ UC of

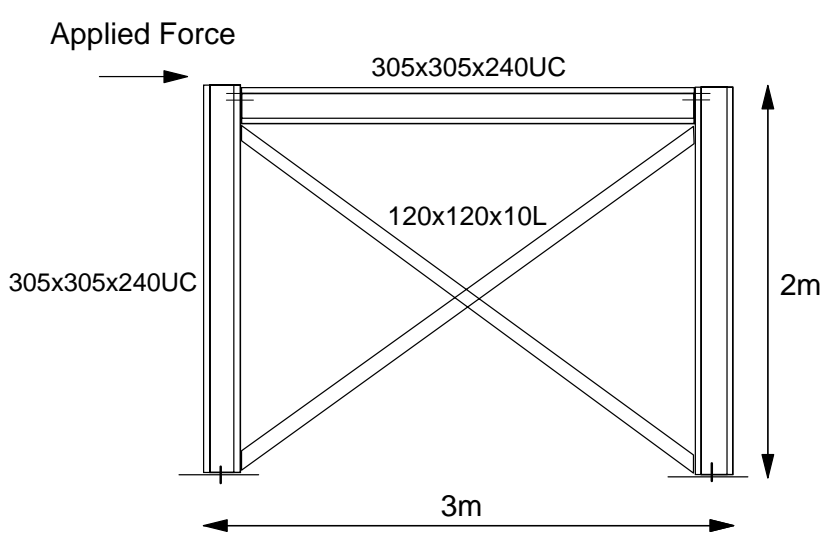

Figure 11. Simple portal with cross-braces S275 steel grade. The bracing angles are taken as sections 120 x 120 x 10 L grade S275 steel with both ends pin-connected to the columns by a single bolt. For simplicity, the gusset plate is assumed thin with negligible flexural stiffness so that rotational spring at connection is ignored. The portal is pinned to ground and the beam is pinned to column, which represents the simplest case of simple construction with beams simply supported on columns and lateral force resisted by a bracing system.

In conventional linear analysis, the compressive angle member is commonly ignored because of its high slenderness. Thus, two linear analyses were carried out as ignoring and considering the presence of compression member. For second-order analysis, again two assumptions are made on using (1) imperfection of L/360 recommended in this paper and (2) a very small imperfection of $\mathrm{L} / 7600$ for comparison. In all design, the design load is assumed when the first member fails except 
in an elastic-plastic analysis where analysis is continued until the load cannot further be increased with increment of displacement. Below is the summary of the design loads of the truss. The results are summarized in Table 6 and Figure 12 presents a load-deflection curve of the node at which the load is applied to.

From this example, a few interesting points are noted as follows.

(1) The conventional approach ignoring bracing members in compression yields a result more conservative than the second-order analysis by 28\%. Apart from this over-designing, the approach is difficult to apply when many bracing members are present and the error depends on the slenderness ratio of the braces. As $\mathrm{L} / \mathrm{r}$ for the brace is in a typical range of 153 here, the error is considered to be representative of a typical braced truss.

(2) The error considering compression member in a linear analysis and second-order analysis based on perfect geometry are both unacceptable in accuracy. This shows a second-order analysis without consideration of imperfections should not be used with section capacity check or even in a second-order analysis.

(3) The common concept that the compression bracing member cannot take much load and therefore ignored in a linear analysis is not correct when the present slenderness ratio is considered. Compression members even as bracings can be considered in an analysis with allowance for their strength and stiffness reductions due to high slenderness and imperfections.

The advantage of the present method over the linear analysis is obvious in this example. The contribution of the compression member can be considered when using the second-order analysis and the actual failure mode in the structure can be manifested, both of the considerations are not possible to consider in a linear analysis with the effective length method.

Table 5. Design Loads of various analysis types

\begin{tabular}{|c|c|c|c|}
\hline Analysis Type & $\begin{array}{l}\text { Design Load at } \\
\text { First Yield } \\
(\mathbf{k N})^{1} \\
\end{array}$ & $\begin{array}{c}\text { Corresponding Force } \\
\text { at } \operatorname{Compression~}^{\operatorname{Brace}^{2}(\mathbf{k N})} \\
\end{array}$ & $\begin{array}{c}\text { Corresponding Force } \\
\text { at Tension Brace }{ }^{2} \\
(\mathrm{kN})\end{array}$ \\
\hline $\begin{array}{l}\text { Linear analysis with design } \\
\text { load assumed at failure of } \\
\text { compression brace }\end{array}$ & 207 & 124 & 124 \\
\hline $\begin{array}{l}\text { Linear analysis ignoring the } \\
\text { presence of compression } \\
\text { brace }\end{array}$ & 430 & / & 517 \\
\hline $\begin{array}{l}\text { Second-order using very } \\
\text { small imperfection (L/7200) }\end{array}$ & 840 & 506 & 504 \\
\hline $\begin{array}{l}\text { Second-order analysis using } \\
\text { L/360 as imperfection }\end{array}$ & 595 & 358 & 357 \\
\hline Elastic-plastic analysis ${ }^{4}$ & 726 & 358 & 517 \\
\hline \multicolumn{4}{|c|}{$\begin{array}{l}\text { Note: 1. Design load is taken as the lateral load causing the bracing member to yield. } \\
\text { 2. The compression or tension force at the design load. } \\
\text { 3. This is the design load calculated from the recommended imperfection in this paper. } \\
\text { 4. Elastic-Plastic buckling load is obtained by simple maintenance of the maximum resistance of the compressive brace } \\
\text { with the external load continues to increase until a mechanism is reached. This method accounts for force and moment } \\
\text { re-distribution among members and its load deflection curve is indicated in Figure 12. }\end{array}$} \\
\hline
\end{tabular}




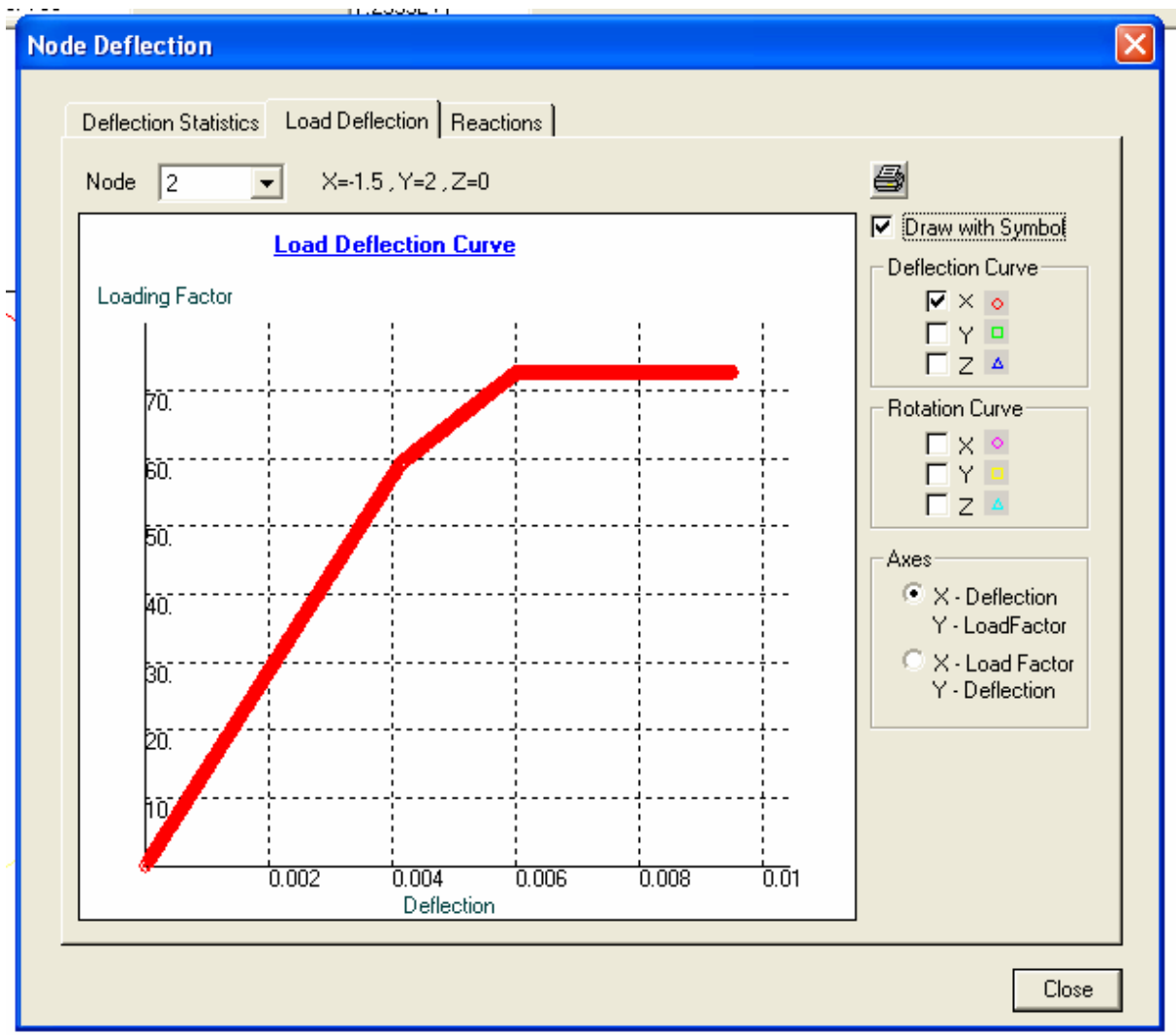

Figure 12. Theoretical Load vs. deflection plot of the portal

\section{CONCLUSIONS AND RECCOMENDATIONS}

In this paper, a second-order $\mathrm{P}-\Delta-\delta$ analysis is developed for angle trusses comprised of slender members. The P- $\Delta$ and P- $\delta$ effect is considered respectively by geometry and curvature updates, with code allowance of imperfections as imperfect frame geometry and initial member curvature. The values of $\delta_{0} / \mathrm{L}$ for equal and unequal angles are suggested and verified by comparison with laboratory tests of angle trusses. It is found that the proposed method gives a conservative design in fulfillment of the code requirements and the same calibrating procedure can obviously be applicable to other national steel structure design codes. The second-order $\mathrm{P}-\Delta-\delta$ method was noted to be a reliable, robust, efficient and convenient design method for steel frames as well as angle trusses. It considers and designs the framed structure as a whole instead of designing members in isolation and separately. The method requires no assumption on effective length and the rotation stiffness of the connection is accounted for by adding rotational spring elements at member ends. This method is more rational when compared with the effective length method. In the present investigation, the stiffness of the rotational spring element can be taken as the stiffness of the gusset plate.

\section{ACKNOWLEDGEMENT}

The authors acknowledge the financial support of "Second-order Analysis and Design of Angle Trusses and Frames” by the Research Grant Council grant from the Hong Kong SAR Government. 


\section{REFERENCES}

[1] Chen WF and Lui EM. Stability design of steel frames. Boca Raton, Florida: CRC Press, 1991.

[2] Trahair, NS. Restrained elastic beam-columns. Journal of the Structural Division, ASCE 1969;95(12):2641-2664.

[3] Goodier, JN. The buckling of compressed bars by torsion and flexure. Cornell Univ Engineering Experimental Station Bulletin, 1941;27 Dec.

[4] Goodier, JN. Flexural-torsional buckling of bars of open section, under bending, eccentric thrust or torsional loads. Cornell Univ Engineering Experimental Station Bulletin 1942; 28 Jan.

[5] Foehl FP. Direct method of designing single angle struts in welded trusses, Design Book of Welding. Lincoln Electric Co., Cleveland, OH; 1948.

[6] Kitipornchai S, Chan SL. Nonlinear finite element analysis of angle and tee beam-columns. Journal of Structural Engineering, ASCE 1987;113(4):721-739.

[7] Trahair NS, Usami T, Galambos TV. Eccentrically loaded single angle columns. Research Report No. 11. Structural Division, Civil and Environmental Engineering Department, School of Engineering and Applied Science, Washington University, St Louis, Missouri, USA; 1969.

[8] Adluri SMR, Madugula MKS. Eccentrically loaded steel angle struts. Engineering Journal, AISC 1992;31(3):59-66.

[9] AISC. Load and resistance factor design specification for structural steel buildings. AISC Inc, Chicago; 1986.

[10] AISC. Specification of allowable stress design. AISC Inc, Chicago; 1989.

[11] Wakabayashi M, Nonaka T. On the buckling strength of angles in transmission towers. Bulleting of the Disaster Prevention Research Institute, Kyoto University, Japan, Nov 1965;15(2):1-18.

[12] Mueller WH, Erzurumlu H. Behaviour and strength of angles in compression: an experimental investigation. Research Report of Civil-Structural Engineering. Division of Engineering and Applied Science. Portland State University, Oregon, USA; 1983.

[13] Ishida A. Experimental study on column carrying capacity of "SHY” steel angles. Yawata Technical Report. Yawata Iron and Steel Co Ltd, Tokyo, Japan; Dec, 1968;265:8564-8582, 8761-8763.

[14] Bathon L, Mueller WH, Kempner L. Ultimate load capacity of single steel angles. Journal of Structural Engineering 1993;119(1):279-300. 
[15] ASCE. Manuals and reports on engineering practice no 52. Guide for Design of Steel Transmission Towers, ASCE, New York; 1988.

[16] Elgaaly M, Davids W, Dagher H. Non-slender single angle struts. Engineering Journal, AISC 1992;31(3):49-59.

[17] NIDA. Non-linear integrated design and analysis computer program manual version 7 ElePlast, NAF Series, User’s Manual. The Hong Kong Polytechnic University, Hong Kong; 2005.

[18] BSI. Structural use of steelwork in building - Part 1: Code of practice for design - Rolled and welded sections”, BS5950, BSI, London; 2000.

[19] CEN. Eurocode 3 Design of steel structures - Part 1-1: General rules and rules for building. CEN, BSI, London; 1992.

[20] Code of practice for structural design of steel structures - A limit state approach. Buildings Department, Hong Kong; 2005.

[21] Chan SL, Cho SH. Design of steel frames using calibrated design curves for buckling strength of hot-rolled members. In: Chan SL, Teng JG, Chung KF, editors. Proceedings of Advances in Steel Structures. Elsevier, 2002. Elsevier Science. 1193-1199

[22] Chan SL. Geometric and material nonlinear analysis of beam-columns and frames using the minimum residual displacement method. International Journal for Numerical Methods in Engineering 1988;26:2657-2669.

[23] BSI. Metallic Materials - Tensile Testing - Part 1: Method of Test at Ambient Temperature, BS EN 10002. BSI, London; 2000. 
[Blank Page] 